\title{
Multiple hormone secretion may indicate worse prognosis in patients with ectopic Cushing's syndrome
}

\author{
leva Lase ${ }^{1}$ (i) $\cdot$ leva Strele $^{2} \cdot$ Malin Grönberg $^{1} \cdot$ Gordana Kozlovacki $^{1} \cdot$ Staffan Welin $^{1} \cdot$ Eva Tiensuu Janson $^{1}$
}

Received: 14 June 2019 / Accepted: 2 December 2019/Published online: 16 January 2020

(C) The Author(s) 2020

\begin{abstract}
Purpose Ectopic Cushing's syndrome (ECS) caused by an ACTH secreting neuroendocrine neoplasm (NEN) is a rare and challenging condition. We aimed to detect predictive and prognostic parameters for ECS patients identified from a retrospective, comprehensive cohort of NENs treated at a tertiary referral center.

Methods Medical records of 886 patients with NENs were reviewed. We identified 51 patients with ECS (33 females/18 men); mean age $52 \pm 15$ years (SD). Clinical parameters including symptoms, biochemical markers, and survival were extracted and further analyzed.

Results The primary tumor was located in the thorax $(n=28)$ or pancreas $(n=15)$ or was of unknown primary origin $(n=8)$. In 30 patients, tumor and ECS were diagnosed simultaneously. In 12 patients, the NEN diagnosis preceded ECS development, with a median time of 43.5 months (range: 9-96), and 10 of these showed radiological tumor progression at ECS diagnosis. Twentyone patients had multiple hormone secretion, which correlated with shorter overall survival (OS), $p=0.012$ (HR 2.4 (95\% CI 1.2-4.9)), as did high morning cortisol, $p=0.037$ (HR $2.3(1.0-5.2)$ ), higher tumor grade, $p=0.044$ (HR $2.3(1.0-5.1)$ ), and diabetes, $p=0.050$ (HR $2.4(1.0-6.0)$ ).

Conclusions Multiple hormone secretion, high morning cortisol, higher tumor grade, and diabetes were correlated with shorter OS. Development of ECS in patients with a non-functioning NEN may indicate tumor progression. Multiple hormone secretion should be considered as a bad prognostic sign in ECS patients and should lead to intensified clinical management.
\end{abstract}

Keywords Ectopic Cushing's syndrome · ACTH · Neuroendocrine $\cdot$ Hypercortisolism · Multiple hormone secretion · Hypokalemia

\section{Introduction}

High levels of plasma cortisol may be due to several different medical disorders but they almost always lead to a severe health condition in the patient. Endogenous Cushing's syndrome (CS) has an estimated incidence of 0.2-5.0 per million people per year [1]. In 5-10\% of these, development of CS is due to an ectopic production of corticotrophin-releasing

Ieva Lase

ieva.lase@medsci.uu.se

1 Department of Medical Sciences, Endocrine Oncology Unit, Uppsala University, SE-751 85 Uppsala, Sweden

2 Department of Public Health and Epidemiology, Riga Stradins University, Dzirciema street 16, Riga LV-1007, Latvia hormone (CRH) or ACTH by a non-pituitary tumor (ectopic ACTH-dependent CS) [1, 2].

The clinical picture of ectopic Cushing's syndrome (ECS) can be the same as in Cushing' s disease, but the rapid onset, severity, and progress of symptoms may suggest an ectopic source [2]. The clinical signs and symptoms include hypertension, high levels of blood glucose (often manifest diabetes mellitus), hypokalemia and metabolic alkalosis, and psychopathology and neurocognitive disorders, among many other manifestations. Severe infections, often caused by opportunistic agents, are also frequently seen due to the immunosuppressive action of cortisol.

The most well-known tumor responsible for ectopic ACTH production is small cell lung carcinoma (SCLC), and among SCLCs, 3.5-50\% is reported to produce ACTH [2]. The reported prevalence range of ECS in patients with SCLC is very wide and probably depends on referral patterns of the patients to specialized clinics as well as small cohort sizes (selection 
bias) [2]. Most of these tumors lack immunohistochemical evidence of neuroendocrine differentiation and are highly malignant with extremely rapid clinical deterioration and short survival, which also can influence the reported prevalence. The second most common cause of ectopic ACTH production is neuroendocrine neoplasms (NENs) of various origins, such as lung $5-40 \%$, pancreas $7.5-42 \%$, and thymus $5-42 \%$ [2]. There are published case reports of ECS in connection with other types of malignancies as well, for example, pheochromocytoma [3, 4], medullary thyroid cancer [5-7], paraganglioma $[8,9]$, prostate cancer $[10,11]$, and even more rare ectopic sources of ACTH secretion [12-15]. Patients with genetically inherited syndromes, which are associated with a risk of development of NENs, can also develop ECS [16-19]. In $12.5-19 \%$ of patients with ECS, the source of ACTH secretion is never found [20,21].

Because of the rarity of ECS, most of the publications are clinical case reports. In the case series published [20-34], the number of included patients is usually less than 50. Only two centers have published studies of $>100$ patients with ECS [23, 35]. Thus, very little is known about the epidemiological, clinical, and molecular features of ACTH secreting NENs, and there is, to our knowledge, only one study published about predictive and prognostic markers of ECS in patients with NENs, indicating that severe hypercortisolism, hypokalemia, diabetes mellitus, and distant metastases were negative predictive factors [35]. The phenomenon of multiple hormone secretion has been described mainly in pancreatic NENs [36-41], while the impact of multiple hormone secretion in patients with ECS is yet unknown.

The aim of this study was to retrospectively analyze a cohort of NEN patients with ECS, referred to a tertiary NET center, in order to describe clinical symptoms and biomarkers of predictive and prognostic impact to identify parameters of clinical significance.

\section{Materials and methods}

\section{Patients}

At our tertiary referral center, we retrospectively reviewed the records of 886 patients with NENs (excluding small bowel NENs), referred to the Department of Endocrine Oncology, Uppsala University Hospital, between 1986 and 2014, to systematically search for patients with ECS. Patients with SCLC were not included in our cohort, since these tumors are not treated at our center and are hypothesized to have a different mechanism behind ACTH production from that of NENs. Fifty-one patients $(6 \%)$ with ECS were identified. The pituitary/adrenal source of CS was excluded initially by hormonal analysis (serum and urinary cortisol, ACTH), functional tests (for example, low- and high-dose dexamethasone test,
CRH stimulation test), imaging (CT and MR), and sinus petrosus sampling (IPSS).

\section{Data}

Data were collected from medical records at Uppsala University Hospital or local hospitals where the first visit took place and included sex, age at diagnosis of tumor and/or ECS, approximate time from first symptoms of hypercortisolism to diagnosis of ECS, clinical symptoms, complications of ECS, blood pressure (BP), body mass index (BMI), and survival data. BP was divided into two groups, as normal $(\leq 139 /$ $89 \mathrm{mmHg}$ ) or arterial hypertension $(\geq 140 / 90 \mathrm{mmHg})$, according to the current guidelines for classification of BP [42]. Survival data were analyzed until March 2018.

All the collected clinical and biochemical parameters were retrospective; they were recorded at NENs and/or ECS diagnosis and before any symptomatic or tumor-directed treatment was started. The accuracy of the data on clinical symptoms and complications depends on how completely the medical history was collected and documented.

Biochemical data included potassium and glucose levels. Hypokalemia was defined as potassium levels $<3.5 \mathrm{mmol} / \mathrm{l}$. Hormone levels recorded included ACTH (ng/l), urine free cortisol (nmol/24 h), morning and midnight serum cortisol $(\mathrm{nmol} / \mathrm{l})$, and other relevant hormones if the levels were abnormal.

Data regarding histological examination (when available) were extracted from medical records; no new immunohistochemical investigations were performed. For the grading of tumors of gastrointestinal origin (GEP-NENs), the WHO 2010 classification of tumors of the digestive system was used [43], and for the grading of thoracic NENs, the WHO 2014 classification of lung cancer was used [44]. In the case of repeated biopsies and histopathological examinations, the highest Ki67 was used in analyses.

\section{Evaluation of hormone levels}

The study covered a long time period, and hormone levels were analyzed at different laboratories and with different methods. Therefore, the upper reference varied slightly between 40 and $72 \mathrm{ng} / \mathrm{l}$ for ACTH, between 230 and $372 \mathrm{nmol} / 24 \mathrm{~h}$ for urine free cortisol (UFC), and between 540 and $800 \mathrm{nmol} / 1$ for morning and $300-330 \mathrm{nmol} / 1$ for evening plasma cortisol. For the calculation of average hormone levels and for analysis of these data, those differences were not considered of importance, since almost all patients had very high hormone levels. Multiples of the upper limit of normal (UNL) were used as well to describe hormone levels in the cohort. When analyzing survival, levels of ACTH, UFC, and cortisol were divided into two groups (low vs. high) by using the median hormone level as cut-off. 


\section{Statistical analysis}

Patient characteristics and biochemical findings were summarized by descriptive statistics: normally distributed data were described as means \pm standard deviation and data with skewed distribution and/or outliers were described as medians, accompanied by the 25th-75th percentile ranges (Q1-Q3). The defined event was death from any cause. Overall survival (OS) was defined as time from diagnosis of NEN and/or ECS until date of death, or if event was not found, censored at date of last observation, 1st of March 2018. Kaplan-Meier plots were used for survival analysis, and the log-rank test was used for comparison. Cox proportional regression was performed for the estimation of hazard ratios (HRs) and confidence intervals (CIs). Correlation was estimated using Spearman's correlation test. The level of statistical significance was set at 0.05. All statistical analyses were performed using IBM SPSS Statistics software (v24, USA).

\section{Results}

As the data were collected retrospectively from patient records, not all the preferred parameters were available for all patients.

\section{Patients}

Among the 51 cases of ECS, there were 18 males and 33 females. Mean age at tumor diagnosis was $51 \pm 15$ years (SD) and at diagnosis of ECS $52 \pm 15$ years (SD). Clinicopathological characteristics of the cohort are presented in Table 1. The primary tumor was located in the pancreas in 15 patients and in the thorax (bronchial or thymus NEN) in 28 patients. There were no patients with ECS due to medullary thyroid carcinoma identified in our cohort. A majority of the pancreatic tumors were G2 and most of the thoracic tumors were atypical carcinoids (patients with SCLC not included). Among the eight patients with ECS and NENs of unknown primary origin, three patients had liver metastases at diagnosis, but the primary tumor was never found, while in five patients, a tumor could not be found despite extensive workup, including octreotide scintigraphy and/or positron emission tomography. Thirty-four patients had documented metastatic disease to one $(n=15)$ or more $(n=19)$ locations at the time of ECS diagnosis.

Immunohistochemical staining for ACTH/CRH was performed in 24 patients: 15 patients were positive for ACTH, two for $\mathrm{CRH}$, and one for both hormones. Six patients had negative staining for both ACTH and CRH (in five of the patients, the immunohistochemical staining was performed on liver metastases and in one patient on the primary tumor) despite metastatic NEN, high circulating ACTH levels and no radiological evidence of pituitary disease. Two of these latter patients had a very acute debut of disease with extremely high cortisol/ACTH levels and need for intensive care due to hypokalemia.

Thirty patients (59\%) were diagnosed simultaneously with ECS and tumor, while $12(23 \%)$ had an initial diagnosis of a NEN without ECS, based on absence of clinical symptoms of $\mathrm{CS}$, normal potassium, and ACTH/cortisol levels. Among those 12 , there was a wide difference in time from diagnosis of tumor to development of ECS, with median time 43.5 months (range: 9-96). Ten of those 12 patients had radiological tumor progression at the time of diagnosis of ECS.

Nine patients (18\%) were initially diagnosed with ECS without a detectable tumor. In five of these patients, ECS was defined as occult since neither primary tumor nor metastatic disease was found and pituitary origin was excluded. One of those patients had cyclic Cushing's syndrome with a need for intensive care during periods of excessive cortisol secretion. In the whole cohort, the median time from first Cushing symptoms to diagnosis of ECS was 2 months (range: $0-12$ ).

A summary of the symptoms and most frequent complications of hypercortisolism observed in the cohort is presented in Table 1. Fifty patients had at least one clinical sign related to Cushing's syndrome at diagnosis.

Diabetes mellitus and arterial hypertension at diagnosis was found in $36(71 \%)$ of patients, respectively. BP at diagnosis was unknown for eight patients.

\section{Biochemical findings}

Patients with ECS had a tendency towards hyperglycemia and hypokalemia. Information about the potassium level at diagnosis was available for 44 patients, and 33 (75\%) of those had hypokalemia. Thirty-two percent of patients had a potassium level $<2.4 \mathrm{mmol} / \mathrm{l}, 23 \%$ had levels between 2.5 and $2.9 \mathrm{mmol} /$ 1 , and $20 \%$ had levels between 3 and $3.4 \mathrm{mmol} / 1$ at diagnosis.

Almost all patients had very high hormone levels. ACTH was $1-2 \times$ ULN in 16 patients, $3-10 \times \mathrm{ULN}$ in 21 patients, and $>11 \times$ ULN in six patients. UFC was $1-2 \times$ ULN in three patients, 3-20 $\times$ ULN in 26 patients, $21-99 \times$ ULN in seven patients, and in eight patients more than $100 \times$ ULN. Mean values of biochemical data and median hormone levels are summarized in Table 2.

Twenty-one patients (41\%) (10 pancreatic NENs and 11 thoracic NENs) had concomitant hypersecretion of other hormones than ACTH from their tumor (Table 3). Five of those had simultaneous hypersecretion of two or more hormones in addition to ACTH. 5-HIAA was elevated in 11 patients, with a median level of $461 \mathrm{ng} / \mathrm{ml}$ (range: 134-2151): normal range < $50 \mathrm{ng} / \mathrm{ml}$; eight of these had thoracic NENs, two pancreatic NENs, and one unknown primary tumor. In 17 patients, hypersecretion of ACTH and other hormones was discovered 
Table 1 Clinicopathological characteristics of 51 patients with ectopic Cushing's syndrome

\begin{tabular}{|c|c|c|c|}
\hline Variable & $N(\%)$ & Symptoms & $N(\%)$ \\
\hline Gender & & Hypertension & $36(71)$ \\
\hline Female & $33(65)$ & Diabetes & $36(71)$ \\
\hline Male & $18(35)$ & Moon face & $35(69)$ \\
\hline Age at diagnosis of tumor (years) & & Central obesity & $32(63)$ \\
\hline$<40$ & $13(25)$ & Muscle weakness & $24(47)$ \\
\hline $41-70$ & $28(55)$ & Ankle edema & $21(41)$ \\
\hline$>71$ & $5(10)$ & Bruising & $19(37)$ \\
\hline No tumor found & $5(10)$ & Psychiatric symptoms & $16(31)$ \\
\hline Tumor localization & & Hirsutism & $14(27)$ \\
\hline Pancreas & $15(29)$ & Thin skin & $8(16)$ \\
\hline Bronchial NENs & $24(47)$ & Striae & $7(14)$ \\
\hline Thymus & $4(8)$ & Hyperpigmentation & $4(8)$ \\
\hline Unknown & $8(16)$ & Amenorrhea & $2(4)$ \\
\hline Metastasis localization at diagnosis of tumor & & Acne & $1(2)$ \\
\hline Liver & $23(45)$ & Hyperhidrosis & $1(2)$ \\
\hline Lymph nodes & $12(23)$ & Baldness & $1(2)$ \\
\hline Bone & $4(8)$ & No typical Cushing symptoms & $1(2)$ \\
\hline Lung & $4(8)$ & Complications & \\
\hline Other & $4(8)$ & Bacterial infections/sepsis & $25(49)$ \\
\hline No metastasis & $20(39)$ & Thromboembolic complications & $11(22)$ \\
\hline Tumor grade & & Fungal infections & $8(16)$ \\
\hline GI-NENs (pancreatic) & & Osteoporosis/osteopenia/fractures & $8(16)$ \\
\hline G1Ki67<=2\% & $0(0)$ & & \\
\hline G2Ki67 3-20\% & $9(60)$ & & \\
\hline G3Ki67 > 20\% & $2(13)$ & & \\
\hline No data & $4(27)$ & & \\
\hline \multicolumn{4}{|l|}{ Lung NENs (bronchial + thymic) } \\
\hline Typical & $1(4)$ & & \\
\hline Atypical & $14(50)$ & & \\
\hline NEC (excluding SCLC) & $8(28)$ & & \\
\hline No data & $5(18)$ & & \\
\hline
\end{tabular}

GI-NEN gastrointestinal neuroendocrine neoplasia, NEN neuroendocrine neoplasia, NEC neuroendocrine carcinoma, SCLC small cell lung carcinoma

simultaneously, while two patients developed ECS first, followed by hypersecretion of other hormones some years later. Two patients had hypersecretion of hormones, resulting in clinical syndromes with typical clinical symptoms (insulinoma and gastrinoma) for 36 and 149 months, respectively, prior to ECS.

Four patients had primary hyperparathyroidism with elevated levels of PTH and persistent hypercalcemia (albumin corrected or ionized calcium). All these patients had thoracic NENs (three atypical bronchial carcinoids and one thymus carcinoid). They were diagnosed with ECS in the 1990s when possibilities for genetic testing for MEN1 were limited, but two of them showed a clinical picture of MEN1 with hyperparathyroidism, pituitary adenoma, and NEN.

Potassium levels were negatively correlated to blood glucose $(\rho=-0.5, p=0.002)$, ACTH $(\rho=-0.4, p=0.01), \mathrm{UFC}$
( $\rho=-0.5, \mathrm{p}=0.002)$, morning cortisol $(\rho=-0.6, p<0.001)$, and evening cortisol $(\rho=-0.5, p=0.032)$ levels. Blood glucose was positively correlated to morning cortisol $(\rho=0.5$, $p=0.004)$. BP and Ki67 did not correlate with potassium or hormone levels.

\section{ECS and survival}

At the end of the study period, ten patients were still alive and 36 had died. Data were not available for five patients. Although the concrete cause of death in ECS patients may be difficult to define due to a very complex clinical picture and overlap of comorbidities, the following causes were retrieved from medical records: progress of tumor $(n=18)$, infections and other ECS-related comorbidities $(n=8)$, complications after adrenalectomy $(n=3)$, multi-organ failure $(n=$ 
Table 2 Biochemical data and hormone levels for patients with ectopic Cushing's syndrome

\begin{tabular}{llll}
\hline Laboratory findings & Number & Mean value \pm SD & Min-max \\
\hline Potassium (mmol/l) & 44 & $2.9 \pm 0.7$ & $1.9-4.4$ \\
Glucose (mmol/l) & 40 & $10.5 \pm 6.2$ & $3.6-29$ \\
Laboratory findings & $N$ & Median & 25 th-75th percentile \\
ACTH (ng/l) & 47 & 156 & $92-341$ \\
UFC (nmol/24 h) & 42 & 4247 & $2726-27,117$ \\
Serum morning cortisol (nmol/l) & 40 & 1318 & $822-2206$ \\
Serum midnight cortisol (nmol/l) & 17 & 1184 & $724-1823$ \\
\hline
\end{tabular}

Upper reference for ACTH 40-72 ng/l, for $24 \mathrm{~h}$ for urine free cortisol 230-372 nmol, for morning plasma cortisol 540-800 nmol/1 and for evening plasma cortisol 300-330 nmol/1

ACTH adrenocorticotropic hormone, UFC urine free cortisol

$1)$, other malignancies $(n=1)$, and myocardial infarction $(n=$ 1). Cause of death was unknown in four patients.

Average follow-up time from tumor diagnosis until end of the study period was 46 months (range 12-104) and from the time of ECS diagnosis to the end of the study period 33 months (range 6-83). Median OS from tumor diagnosis was 46 months (95\% CI 20-71), with a 5-year survival of $41 \%$. OS from the time of ECS diagnosis was 33 months $(95 \%$ CI 16-50), with a 5-year survival of $30 \%$. There was no difference in OS between thoracic NENs and pancreatic NENs.

Patients who died due to ECS-related comorbidities had a shorter survival, 5 months vs. 18 months, compared to those who died due to tumor progression $(p=0.001)$. Patients with multiple hormone secretion had shorter survival, 32 months vs. 95 months, compared to those with ECS only $(p=0.009)$, confirmed by univariate Cox regression analysis, $p=0.012$ (HR 2.4 (95\% CI 1.2-4.9)). Multiple hormone secretion was a statistically significant independent variable in multivariate Cox regression analysis, $p=0.044$ (HR 3.9 (95\% CI 1.0414.7)). Furthermore, shorter OS was found in patients with diabetes: 33 months vs. 104 months $(p=0.041)$, higher than median morning cortisol levels: 33 months vs. 92 months ( $p=$ 0.031 ), and tumors with Ki67 > 20\%: 19 months vs. 65 months ( $p=0.036)$, compared to non-diabetic patients, patients with lower than median morning cortisol, and tumors with Ki67 < $20 \%$, respectively. Furthermore, patients with hypokalemia at diagnosis showed a trend towards shorter OS in our cohort: 32 vs. 76 months $(p=0.067)$. Survival data obtained from Cox regression models are summarized in Table 4 and KaplanMeier OS curves for those parameters are shown in Fig. 1.

\section{Discussion}

In this comprehensive cohort of patients with ACTHproducing NENs, we identified multiple hormone secretion as the strongest indicator of worse prognosis. In addition, high morning cortisol, high blood glucose (diabetes mellitus), and higher tumor grade had a similar impact on OS, confirming

Table 3 Overview of concomitant hypersecretion of other hormones than ACTH only and relation to tumor site in patients with ectopic Cushing's syndrome

\begin{tabular}{lllll}
\hline Hormone secretion in addition to ACTH & Patients with multiple hormone secretion & \multicolumn{2}{l}{ Tumor site } & \\
\cline { 2 - 5 } & $N=21$ & Pancreas & $\begin{array}{c}\text { Lungs } \\
N=10\end{array}$ & $\begin{array}{c}\text { Thymus } \\
N=1\end{array}$ \\
& & $N=9$ & Unknown \\
& & - & 6 & 1 \\
\hline 5-HIAA & 8 & - & 3 & - \\
Calcitonin & 3 & 2 & - & - \\
Gastrin & 2 & 3 & - & - \\
Glucagon & 3 & 1 & 1 & - \\
Calcitonin+5-HIAA & 2 & 1 & - & - \\
Gastrin+5-HIAA & 1 & 1 & - & - \\
Gastrin + Proinsulin & 1 & 1 & - & - \\
Insulin + Gastrin + VIP & 1 & & -
\end{tabular}

ACTH adrenocorticotropic hormone, VIP vasoactive intestinal peptide, 5-HIAA 5-hydroxyindoleacetic acid 
Table 4 Univariate and multivariate analysis of prognostic parameters of survival in ectopic Cushing's syndrome

\begin{tabular}{|c|c|c|c|}
\hline Variable & & $\mathrm{HR}(95 \% \mathrm{CI})$ & $p$ value \\
\hline \multicolumn{4}{|l|}{ Univariate analysis } \\
\hline Hormone secretion & ACTH only vs. multiple hormones & $2.4(1.2-4.9)$ & 0.012 \\
\hline Morning cortisol nmol/1 & $\leq 1318$ vs. $>1318$ & $2.3(1.0-5.2)$ & 0.037 \\
\hline Tumor grade (WHO 2010) & I + II vs. III & $2.3(1.0-5.1)$ & 0.044 \\
\hline Diabetes & Yes vs. No & $2.4(1.0-6.0)$ & 0.050 \\
\hline Potassium mmol/1 & $<3.5$ vs. $\geq 3.5$ & $2.2(0.9-5.5)$ & 0.077 \\
\hline Evening cortisol nmol/1 & $\leq 1184$ vs. $>1184$ & $2.5(0.7-9.2)$ & 0.164 \\
\hline Tumor localization & Thoracic vs. pancreas & $0.7(0.3-1.5)$ & 0.432 \\
\hline ACTH ng/ml & $\leq 156$ vs. $>156$ & $1.2(0.6-2.5)$ & 0.530 \\
\hline UFC nmol/24 h & $\leq 4247$ vs. $>4247$ & $0.9(0.4-1.8)$ & 0.744 \\
\hline \multicolumn{4}{|l|}{ Multivariate analysis } \\
\hline Hormone secretion $^{\mathrm{a}}$ & ACTH only vs. multiple hormones & $3.9(1.0-14.7)$ & 0.044 \\
\hline
\end{tabular}

Hazard ratio (HR) and 95\% confidence intervals (CIs) obtained from Cox regression models. ACTH, UFCm, and cortisol are divided in two groups (low vs. high) by using the median hormone level as cut-off

ACTH adrenocortical hormone, UFC urine free cortisol

${ }^{\text {a }}$ Adjusted for morning cortisol levels, diabetes, Ki67, and hypokalemia

results from a previous study [35]. Hypokalemia showed a tendency towards shorter OS as well.

ACTH production from NENs is a very rare but serious condition, almost always creating a big challenge for physicians as regards diagnostic and treatment issues. In this comprehensive cohort from Uppsala ENETs Centre of Excellence, $6 \%$ of all patients with NENs were identified as having ECS in contrast to another similar cohort where only $3.2 \%$ were identified [32]. There was a predominance of women (ratio 2:1) in the present material, which is consistent with data in other series [23, 28, 32]. Mean age at diagnose of ECS was 52 years in contrast to a number of previous studies, where it varied from 27.6 to 49 years $[20,21,23,24,26,32]$. The age differences between different cohorts could be explained by the proportion of different NEN types included, since thymus NENs tend to occur in younger persons [29, 34], while SCLC is more frequent in older individuals [45].

SCLC patients were not included in our cohort. SCLC with ECS has a very serious course, with rapid deterioration and short survival. Had those patients been included, it would have been difficult to delineate the clinical course of ECS in other NENs, which was the purpose of our study. The different biology between SCLC and NENs is further indicated by the fact that the molecular defects behind ectopic ACTH secretion may not be similar [1]. Molecular biology studies have proposed different mechanisms for ACTH production between poorly differentiated tumors, SCLC, and neuroendocrine tumors. For example, SCLC cells process proopiomelanocortin (POMC) in an aberrant way, which results in the release of $\mathrm{ACTH}$ precursors of large molecular weight, such as pro-
ACTH, while NET cells process POMC, normally releasing large amounts of intact ACTH into the circulation [46].

ECS has been reported to occur more frequently in thoracic NENs than in pancreatic NENs [2, 47], which is supported by the results of the present study ( 55 vs. $29 \%$ ). However, the incidence of ECS due to pancreatic NENs was higher in our cohort than previously reported $[20,23]$. This is probably due to a selection bias, since our study was performed in a specialized center for endocrine oncology. We could not detect any difference in OS based on origin of the primary tumor.

In eight patients in our cohort, the primary tumor was never found. In these cases, ECS was suspected either due to metastatic disease $(n=3)$ or to negative pituitary MRI/IPSS in patients with a very aggressive course of Cushing's syndrome and absence of detectable tumor $(n=5)$. It should also be noted that the study period covered almost 30 years, and some patients were investigated before the era of positron emission tomography, which could explain why some small primary tumors were never found.

More than a half of the patients were diagnosed simultaneously with tumor and ECS. In patients in whom ECS developed subsequently, the ECS diagnosis was almost always associated with radiological progression of disease. Median OS in this cohort was 46 months, which is longer than previously reported $[28,32]$. This observed difference may depend on differences in patients included, since we did not include SCLC.

There is a study showing significantly shorter 5-year survival in ECS patients compared to those with non-functioning NENs [32]. Mortality is high during the first time period after 
a

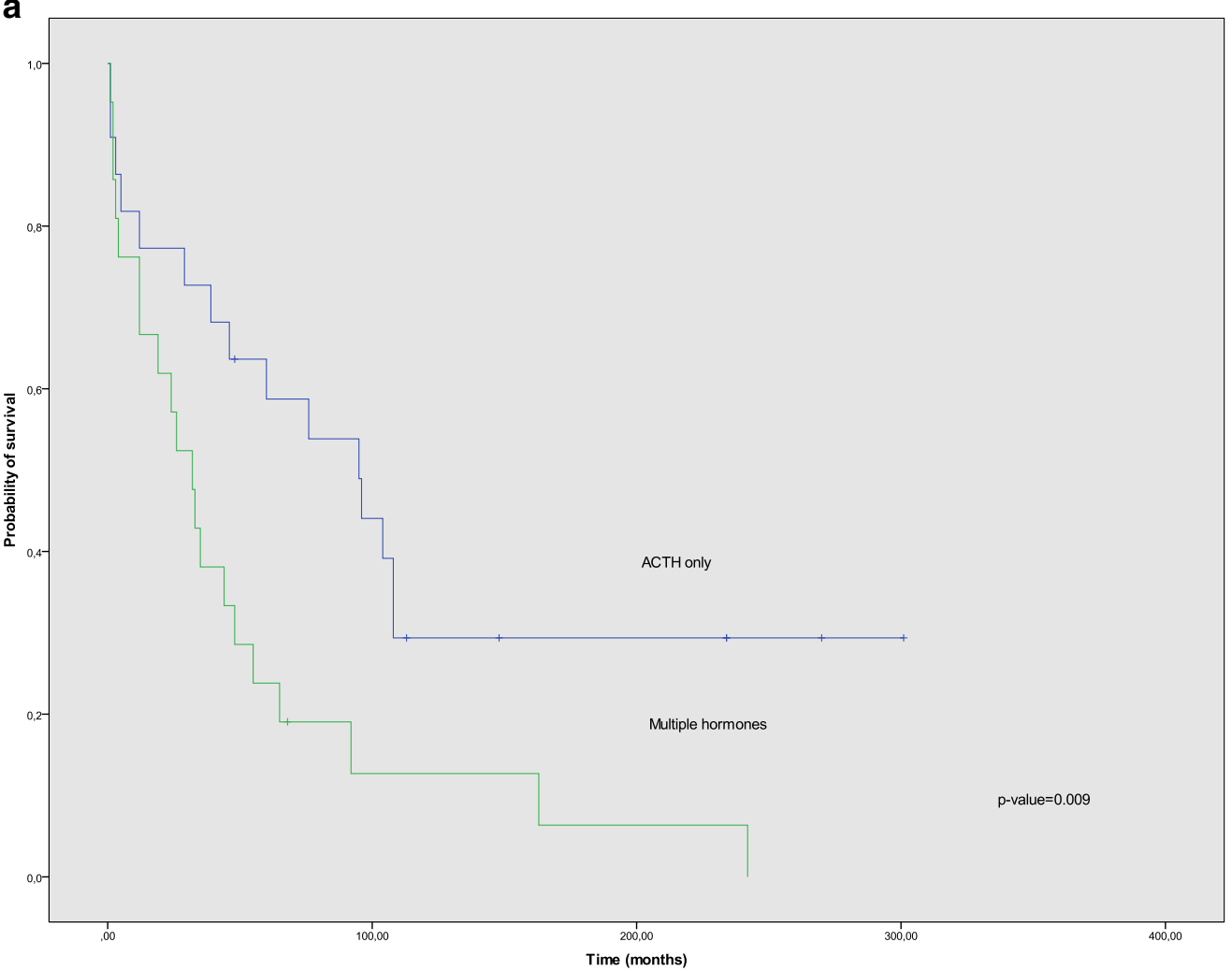

b

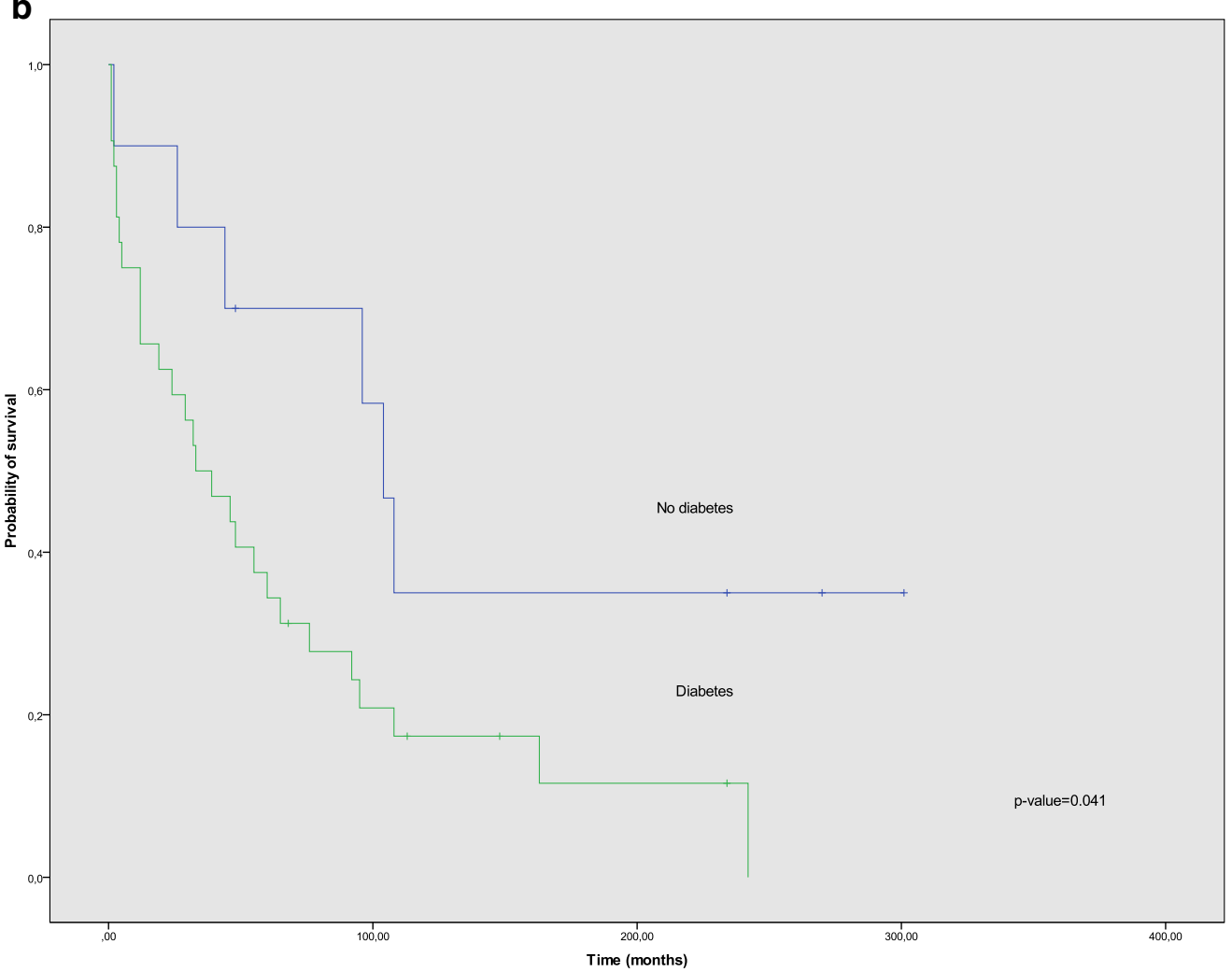

Fig. 1 Kaplan-Meier overall survival (OS) curves for patients with ectopic Cushing's syndrome (ECS) according to different clinical and

adrenocorticotropic hormone (ACTH) or ACTH + other hormones (multiple hormone secretion). b OS according to presence of diabetes at biochemical parameters. a OS according to either tumor secretion of only diagnosis of tumor. $\mathbf{c}$ OS according to morning cortisol levels at diagnosis 


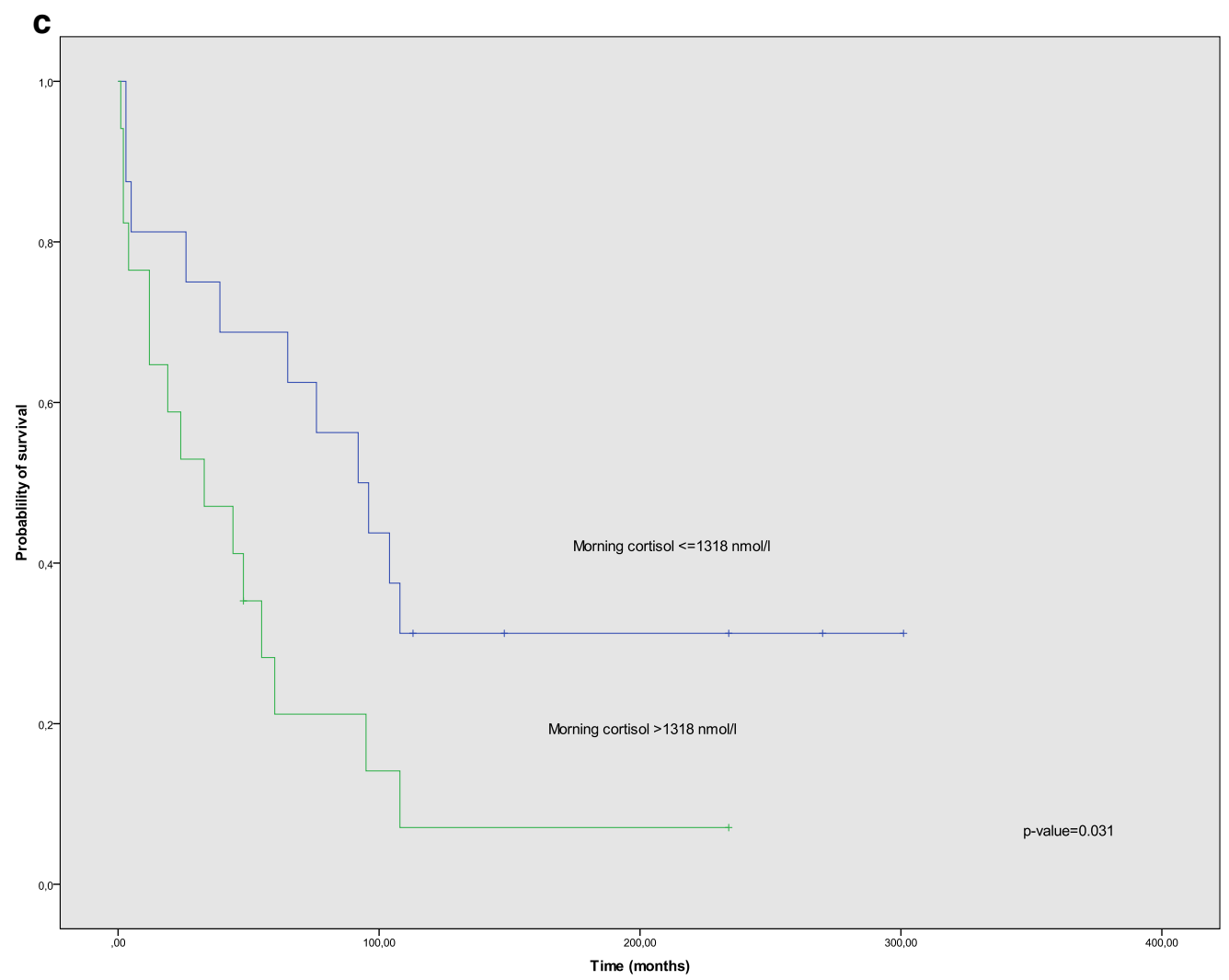

Fig. 1 (continued)

ECS diagnosis, mostly due to complications of hypercortisolism [41]. We found very high hormone levels at ECS diagnosis, suggesting that even though a patient with ECS has a histopathologically well-differentiated tumor (most of our patients had G2 tumors), prognosis may be worse than in patients with non-functioning NENs. Others have also described hypercortisolism as a negative predictive factor in ECS [35].

Almost half of our patients had multiple hormone secretion, which usually appeared simultaneously with the ECS diagnosis. The hormone which was elevated most frequently was U-5-HIAA, dominating in thoracic NENs, followed by calcitonin. There was no evidence of concurrent presence of small bowel NEN or medullary thyroid carcinoma. Patients with multiple hormone secretion had significantly shorter OS. Multiple hormone secretion has been described in pancreatic NENs [36-41], suggesting that there is a trend towards shorter survival in patients with multiple hormone secretion $[36,40]$. However, there are as yet no published data on how concomitant hormone secretion influences OS in thoracic NENs or in patients with ECS. Our findings suggest that multiple hormone secretion can also be found in thoracic NENs, leading to worse prognosis compared to that of patients with ECS only. This indicates that at diagnosis of ECS, other hormones should be measured, especially U-5-HIAA and calcitonin, in order to identify patients who need intensified treatment and follow-up.

Severe hypokalemia, often requiring long periods of hospitalization and intensive care, is a well-known clinical challenge in patients with ECS. This is fully supported by the results of the present study, where $75 \%$ of patients had potassium levels $<3.5 \mathrm{mmol} / \mathrm{l}$ at diagnosis. Hypokalemia was inversely related to hormone levels and negatively affected OS compared to normokalemic patients in our cohort (32 vs. 76 months), which confirms the significance of this metabolic disturbance. Presence of diabetes at diagnosis also had a negative impact on OS compared to non-diabetic ECS patients (33 vs. 104 months). Davi et al. describe similar findings in their cohort regarding negative prognostic factors in ECS [35].

In conclusion, multiple hormone secretion can occur in ECS patients with NENs of both thoracic and pancreatic origin. Patients with multiple hormone secretion as well as high morning cortisol levels and diabetes have worse prognosis, and these patients should be monitored carefully and probably treated more aggressively. Development of ECS in patients with previously known non-functioning NEN may indicate radiological progression of disease. To further improve our knowledge about ECS, multicenter studies are needed with large, prospective cohorts and standardized inclusion criteria. 
Authors' Contributions E.T.J., S.W., and I.L. conceptualized the project and designed the study; I.L. acquired all the data and G.K. contributed to data acquisition; I.L., M.G., and I.S. analyzed the data; I.L. wrote the main manuscript. All the authors interpreted the data, drafted the article, revised it, and approved the final version. Study supervision was performed by E.T.J and S.W.

Funding information Open access funding provided by Uppsala University. This study was funded by the Swedish Cancer Society (grant number CAN 2017/348 [Eva Tiensuu Janson]), the Lions Foundation for Cancer Research at Uppsala University Hospital, and the Selander Foundation and Söderbergs Foundation at Uppsala University.

\section{Compliance with ethical standards}

Conflict of interest The authors declare that they have no competing interests.

Ethical approval All procedures performed in this study were in accordance with the ethical standards of the institutional and/or national research committee and with the 1964 Declaration of Helsinki and its later amendments, or comparable ethical standards. The study was approved by the local ethics committee, Regionala etikprövningsnämnden (EPN), in Uppsala, Sweden.

Informed consent The need for informed consent was waived by the local ethics committee.

Open Access This article is licensed under a Creative Commons Attribution 4.0 International License, which permits use, sharing, adaptation, distribution and reproduction in any medium or format, as long as you give appropriate credit to the original author(s) and the source, provide a link to the Creative Commons licence, and indicate if changes were made. The images or other third party material in this article are included in the article's Creative Commons licence, unless indicated otherwise in a credit line to the material. If material is not included in the article's Creative Commons licence and your intended use is not permitted by statutory regulation or exceeds the permitted use, you will need to obtain permission directly from the copyright holder. To view a copy of this licence, visit http://creativecommons.org/licenses/by/4.0/.

\section{References}

1. Lacroix A, Feelders RA, Stratakis CA, Nieman LK (2015) Cushing's syndrome. Lancet (London, England) 386(9996):913927. https://doi.org/10.1016/s0140-6736(14)61375-1

2. Alexandraki KI, Grossman AB (2010) The ectopic ACTH syndrome. Reviews in Endocrine and Metabolic Disorders 11(2): 117-126. https://doi.org/10.1007/s11154-010-9139-z

3. van Dam PS, van Gils A, Canninga-van Dijk MR, de Koning EJP, Hofland LJ, de Herder WW (2002) Sequential ACTH and catecholamine secretion in a phaeochromocytoma. Eur J Endocrinol 147(2): 201-206. https://doi.org/10.1530/eje.0.1470201

4. Folkestad L, Andersen MS, Nielsen AL, Glintborg D (2014) A rare cause of Cushing's syndrome: an ACTH-secreting phaeochromocytoma. BMJ Case Reports. https://doi.org/10.1136/ bcr-2014-205487

5. Hammami MM, Duaiji N, Mutairi G, Aklabi S, Qattan N, Abouzied MEM et al (2015) Case report of severe Cushing's syndrome in medullary thyroid cancer complicated by functional diabetes insipidus, aortic dissection, jejunal intussusception, and paraneoplastic dysautonomia: remission with sorafenib without reduction in cortisol concentration. BMC Cancer 15(1):624. https:// doi.org/10.1186/s12885-015-1620-3

6. Marques P, da Silva Vieira M, Bugalho MJ (2015) Ectopic Cushing in a patient with medullary thyroid carcinoma: hypercortisolism control and tumor reduction with Sunitinib. Endocrine 49(1):290 292. https://doi.org/10.1007/s12020-014-0352-5

7. Matheny LN, Wilson JR, Baum HBA (2016) Ectopic ACTH production leading to diagnosis of underlying medullary thyroid carcinoma. Journal of Investigative Medicine High Impact Case Reports 4(2):2324709616643989. https://doi.org/10.1177/ 2324709616643989

8. Serra F, Duarte S, Abreu S, Marques C, Cassis J, Saraiva M (2013) Cushing's syndrome due to ectopic ACTH production by a nasal paraganglioma. Endocrinology, Diabetes \& Metabolism Case Reports 2013:130038. https://doi.org/10.1530/EDM-13-0038

9. Park HK, Park CM, Ko KH, Rim MS, Kim YI, Hwang JH et al (2000) A case of Cushing's syndrome in ACTH-secreting mediastinal paraganglioma. The Korean Journal of Internal Medicine 15(2):142-146. https://doi.org/10.3904/ kjim.2000.15.2.142

10. Alwani RA, Neggers SJ, van der Klift M, Baggen MG, van Leenders GJ, van Aken MO et al (2009) Cushing's syndrome due to ectopic ACTH production by (neuroendocrine) prostate carcinoma. Pituitary. 12(3):280-283. https://doi.org/10.1007/s11102-0080100-z

11. Alshaikh OM, Al-Mahfouz AA, Al-Hindi H, Mahfouz AB, Alzahrani AS (2010) Unusual cause of ectopic secretion of adrenocorticotropic hormone: Cushing syndrome attributable to small cell prostate cancer. Endocrine Practice 16(2):249-254. https://doi.org/ 10.4158/ep09243.cr

12. Mendoza CF, Ontiveros P, Xibille DX, Rivera MH (2015) Ectopic ACTH secretion (EAS) associated to a well-differentiated peritoneal mesothelioma: case report. BMC Endocr Disord 15(1):40. https://doi.org/10.1186/s12902-015-0031-4

13. Chentli F, Terki N, Azzoug S (2016) Ectopic adrenocortical carcinoma located in the ovary. Eur J Endocrinol 175(4):K17-K23. https://doi.org/10.1530/eje-16-0224

14. Dacruz T, Kalhan A, Rashid M, Obuobie K (2016) An ectopic ACTH secreting metastatic parotid tumour. Case Reports in Endocrinology 2016:1-4. https://doi.org/10.1155/2016/4852907

15. Park S, Kim M-H, Kim JH, Kim T-O, Kim TH, So H et al (2014) Cushing's syndrome caused by an ACTH-producing neuroendocrine carcinoma of the gallbladder. Korean Journal of Medicine 87(1):67-71. https://doi.org/10.3904/kjm.2014.87.1.67

16. Hasani-Ranjbar S, Rahmanian M, Ebrahim-Habibi A, Soltani A, Soltanzade A, Mahrampour E et al (2014) Ectopic Cushing syndrome associated with thymic carcinoid tumor as the first presentation of MEN1 syndrome-report of a family with MEN1 gene mutation. Familial Cancer 13(2):267-272. https://doi.org/10.1007/ s10689-013-9692-1

17. Li X, Su J, Zhao L, Wu J, Ding X, Fang F et al (2014) Familial Cushing syndrome due to thymic carcinoids in a multiple endocrine neoplasia type 1 kindred. Endocrine 47(1):183-190. https://doi.org/ 10.1007/s12020-013-0141-6

18. Singer K, Heiniger N, Thomas I, Worden FP, Menon RK, Chen M (2014) Ectopic Cushing syndrome secondary to metastatic medullary thyroid cancer in a child with multiple endocrine neoplasia syndrome type 2B: clues to early diagnosis of the paraneoplastic syndromes. J Pediatr Endocrinol Metab 27(9):993-996. https://doi. org/10.1515/jpem-2013-0456

19. Hatipoglu E, Kepicoglu H, Rusen E, Kabasakal L, Gundogdu S, Kadioglu P (2013) Von Hippel Lindau disease with metastatic pancreatic neuroendocrine tumor causing ectopic Cushing's syndrome. Neuro Endocrinology Letters 34(1):9-13

20. Isidori AM, Kaltsas GA, Pozza C, Frajese V, Newell-Price J, Reznek RH et al (2006) The ectopic Adrenocorticotropin 
syndrome: clinical features, diagnosis, management, and long-term follow-up. The Journal of Clinical Endocrinology \& Metabolism 91(2):371-377. https://doi.org/10.1210/jc.2005-1542

21. Ilias I, Torpy DJ, Pacak K, Mullen N, Wesley RA, Nieman LK (2005) Cushing's syndrome due to ectopic corticotropin secretion: twenty years' experience at the national institutes of health. J Clin Endocrinol Metab 90(8):4955-4962. https://doi.org/10.1210/jc. 2004-2527

22. Imura H, Imura H, Matsukura S, Matsukura S, Yamamoto H, Yamamoto H et al (1975) Studies on ectopic ACTH-producing tumors. II. Clinical and biochemical features of 30 cases. Cancer 35(5):1430-1437. https://doi.org/10.1002/1097-0142(197505)35: 5<1430::AID-CNCR2820350529>3.0.CO;2-O

23. Aniszewski JP, Young WF Jr, Thompson GB, Grant CS, van Heerden JA (2001) Cushing syndrome due to ectopic adrenocorticotropic hormone secretion. World J Surg 25(7):934-940. https:// doi.org/10.1007/s00268-001-0032-5

24. Torpy DJ, Mullen N, Ilias I, Nieman LK (2002) Association of Hypertension and Hypokalemia with Cushing's syndrome caused by ectopic ACTH secretion. Ann N Y Acad Sci 970(1):134-144. https://doi.org/10.1111/j.1749-6632.2002.tb04419.x

25. Salgado LR, Villares Fragoso MCB, Knoepfelmacher M, Machado MC, Domenice S, Pereira MAA et al (2006) Ectopic ACTH syndrome: our experience with 25 cases. Eur J Endocrinol 155(5):725733. https://doi.org/10.1530/eje.1.02278

26. Bhansali A, Walia R, Rana SS, Dutta P, Radotra BD, Khandelwal N et al (2009) Ectopic Cushing's syndrome: experience from a tertiary care Centre. Indian J Med Res 129(1):33-41

27. Doi M, Sugiyama T, Izumiyama H, Yoshimoto T, Hirata Y (2010) Clinical features and management of ectopic ACTH syndrome at a single institute in Japan. Endocr J 57(12):1061-1069. https://doi. org/10.1507/endocrj.K10E-265

28. Ejaz S, Vassilopoulou-Sellin R, Busaidy NL, Hu MI, Waguespack SG, Jimenez C et al (2011) Cushing syndrome secondary to ectopic adrenocorticotropic hormone secretion. Cancer. 117(19):43814389. https://doi.org/10.1002/cncr.26029

29. Neary NM, Lopez-Chavez A, Abel BS, Boyce AM, Schaub N, Kwong K et al (2012) Neuroendocrine ACTH-producing tumor of the thymus - experience with 12 patients over 25 years. The Journal of Clinical Endocrinology \& Metabolism 97(7):22232230. https://doi.org/10.1210/jc.2011-3355

30. Maragliano R, Vanoli A, Albarello L, Milione M, Basturk O, Klimstra DS et al (2015) ACTH-secreting pancreatic neoplasms associated with Cushing syndrome: clinicopathologic study of 11 cases and review of the literature. Am J Surg Pathol 39(3):374-382. https://doi.org/10.1097/PAS.0000000000000340

31. Davi MV, Cosaro E, Piacentini S, Reimondo G, Albiger N, Arnaldi $\mathrm{G}$ et al (2016) Clinicopathologic features, treatments and survival of patients with ectopic Cushing's syndrome from neuroendocrine tumors: data from an Italian multicenter study. Neuroendocrinology 103:16

32. Kamp K, Alwani RA, Korpershoek E, Franssen GJH, de Herder WW, Feelders RA (2016) Prevalence and clinical features of the ectopic ACTH syndrome in patients with gastroenteropancreatic and thoracic neuroendocrine tumors. Eur J Endocrinol 174(3): 271-280. https://doi.org/10.1530/EJE-15-0968

33. the Groupe Français des Tumeurs E, More J, Young J, Reznik Y, Raverot G, Borson-Chazot F et al (2011) Ectopic ACTH syndrome in children and adolescents. The Journal of Clinical Endocrinology \& Metabolism. 96(5):1213-1222. https://doi.org/10.1210/jc.20102276

34. Chen YY, Li SQ, Liu HS, Qin YZ, Li L, Huang C et al (2016) Ectopic adrenocorticotropic hormone syndrome caused by neuroendocrine tumors of the thymus: 30-year experience with 16 patients at a single institute in the People's Republic of China. Oncotargets and Therapy 9:2193-2201. https://doi.org/10.2147/ OTT.S100585

35. Davi' MV, Cosaro E, Piacentini S, Reimondo G, Albiger N, Arnaldi G et al (2017) Prognostic factors in ectopic Cushing's syndrome due to neuroendocrine tumors: a multicenter study. Eur J Endocrinol 176(4):453-461. https://doi.org/10.1530/EJE-16-0809

36. Crona J, Norlén O, Antonodimitrakis P, Welin S, Stålberg P, Eriksson B et al (2016) Multiple and secondary hormone secretion in patients with metastatic pancreatic neuroendocrine tumours. The Journal of Clinical Endocrinology \& Metabolism 101(2):445-452. https://doi.org/10.1210/jc.2015-2436

37. Eriksson B, Arnberg H, Lindgren PG, Lorelius LE, Magnusson A, Lundqvist $\mathrm{G}$ et al (1990) Neuroendocrine pancreatic tumours: clinical presentation, biochemical and histopathological findings in 84 patients. J Intern Med 228(2):103-113

38. Wynick D, Williams SJ, Bloom SR (1988) Symptomatic secondary hormone syndromes in patients with established malignant pancreatic endocrine tumors. N Engl J Med 319(10):605-607. https://doi. org/10.1056/nejm198809083191003

39. Chiang HC, O'Dorisio TM, Huang SC, Maton PN, Gardner JD, Jensen RT (1990) Multiple hormone elevations in ZollingerEllison syndrome. Prospective study of clinical significance and of the development of a second symptomatic pancreatic endocrine tumor syndrome. Gastroenterology 99(6):1565-1575

40. de Mestier L, Hentic O, Cros J, Walter T, Roquin G, Brixi H et al (2015) Metachronous hormonal syndromes in patients with pancreatic neuroendocrine tumors: a case-series study. Ann Intern Med 162(10):682-689. https://doi.org/10.7326/m14-2132

41. Zandee WT, Kamp K, van Adrichem RC, Feelders RA, de Herder WW (2017) Effect of hormone secretory syndromes on neuroendocrine tumor prognosis. Endocr Relat Cancer 24(7):R261-RR74. https://doi.org/10.1530/ERC-16-0538

42. Mancia G, Fagard R, Narkiewicz K, Redon J, Zanchetti A, Bohm $\mathrm{M}$ et al (2013) $2013 \mathrm{ESH} / \mathrm{ESC}$ guidelines for the management of arterial hypertension: the task force for the Management of Arterial Hypertension of the European Society of Hypertension (ESH) and of the European Society of Cardiology (ESC). Eur Heart J 34(28): 2159-2219. https://doi.org/10.1093/eurheartj/eht151

43. Bosman FT (2010) International Agency for Research on C. In: World Health O (ed) WHO Classification of Tumours of the Digestive System. IARC Press, Lyon, p 4

44. Travis WD, Brambilla E, Nicholson AG, Yatabe Y, Austin JHM, Beasley MB et al (2015) The 2015 World Health Organization classification of lung tumors: impact of genetic, clinical and radiologic advances since the 2004 classification. J Thorac Oncol 10(9): 1243-1260. https://doi.org/10.1097/JTO.0000000000000630

45. Khakwani A, Rich AL, Tata LJ, Powell HA, Stanley RA, Baldwin DR et al (2014) Small-cell lung cancer in England: trends in survival and chemotherapy using the National Lung Cancer Audit. PLoS One 9(2):e89426. https://doi.org/10.1371/journal.pone. 0089426

46. Terzolo M, Reimondo G, Ali A, Bovio S, Daffara F, Paccotti P et al (2001) Ectopic ACTH syndrome: molecular bases and clinical heterogeneity. Annals of Oncology 12(Suppl 2):S83-S87

47. Isidori AM, Lenzi A (2007) Ectopic ACTH syndrome. Arquivos Brasileiros de Endocrinologia e Metabologia 51(8):1217-1225

Publisher's note Springer Nature remains neutral with regard to jurisdictional claims in published maps and institutional affiliations. 